\title{
Early Treatment With Alglucosidase Alfa Prolongs Long-Term Survival of Infants With Pompe Disease
}

\author{
PRIYA S. KISHNANI, DEYA CORZO, NANCY D. LESLIE, DANIEL GRUSKIN, ANS VAN DER PLOEG, JOHN P. CLANCY, \\ ROSELLA PARINI, GILLES MORIN, MICHAEL BECK, MISLEN S. BAUER, MIKAEL JOKIC, CHEN-EN TSAI, \\ BRIAN W. H. TSAI, CLAIRE MORGAN, TARA O'MEARA, SUSAN RICHARDS, ELISA C. TSAO, AND HANNA MANDEL
}

\begin{abstract}
Department of Pediatrics [P.S.K.], Duke University Medical Center, Durham, North Carolina 27710; Department of Clinical Research [D.C., C.M., T.O., S.R., E.C.T.], Genzyme Corporation, Cambridge, Massachusetts 02142; Department of Pediatrics [N.D.L.], Cincinnati Children's Hospital Medical Center, Cincinnati, Ohio 45229; Department of Genetics [D.G.], Emory University Medical Center, Atlanta, Georgia 30332; Division of Metabolic Diseases and Genetics [A.P.], Erasmus Medical Center, Rotterdam 3015G, The Netherlands; Department of Pediatrics [J.P.C.], University of Alabama at Birmingham, Birmingham, Alabama 35233; Department of Pediatrics [R.P.], University Milano-Bicocca, Milan 20052, Italy; Département de Pédiatrie [G.M.], CHU Amiens, Amiens 80054, France; Metabolic Unit [M.B.], Universitäts-Kinderklinik Mainz, Mainz 55131, Germany; Department of Genetics [M.S.B.], Children's Hospital, Miami, Florida 33155; Practicien Hospitalier [M.J.], Réanimation Pédiatrique, Caen 14033, France; Tzu-Chi General Hospital [C.-E.T.], Hua-Lien,

Taiwan 970, Republic of China; Chi-Mei Foundation Hospital [B.W.H.T.], Yung-Kang City, Taiwan 710, Republic of China; Metabolic Unit [H.M.], Rambam Medical Centre, Haifa 35254, Israel
\end{abstract}

\begin{abstract}
In a previous 52-wk trial, treatment with alglucosidase alfa markedly improved cardiomyopathy, ventilatory function, and overall survival among 18 children $<7$ mo old with infantile-onset Pompe disease. Sixteen of the 18 patients enrolled in an extension study, where they continued to receive alglucosidase alfa at either 20 $\mathrm{mg} / \mathrm{kg}$ biweekly $(n=8)$ or $40 \mathrm{mg} / \mathrm{kg}$ biweekly $(n=8)$, for up to a total of $3 \mathrm{y}$. These children continued to exhibit the benefits of alglucosidase alfa at the age of 36 mo. Cox regression analyses showed that over the entire study period, alglucosidase alfa treatment reduced the risk of death by $95 \%$, reduced the risk of invasive ventilation or death by $91 \%$, and reduced the risk of any type of ventilation or death by $87 \%$, compared with an untreated historical control group. Cardiomyopathy continued to improve and 11 patients learned and sustained substantial motor skills. No significant differences in either safety or efficacy parameters were observed between the 20 and $40 \mathrm{mg} / \mathrm{kg}$ biweekly doses. Overall, long-term alglucosidase alfa treatment markedly extended survival as well as ventilation-free survival and improved cardiomyopathy. (Pediatr Res 66: 329-335, 2009)
\end{abstract}

$\mathrm{P}$ ompe disease is characterized by a deficiency of acid $\alpha$-glucosidase (GAA). The GAA enzyme degrades lysosomal glycogen, and insufficient GAA activity causes glycogen to accumulate in various tissues. Accumulation of lysosomal glycogen in cardiac muscle and skeletal muscle causes progressive cardiomyopathy and generalized muscle weakness and hypotonia, resulting in severely delayed motor development and cardiorespiratory failure (1-3).

Received February 6, 2009; accepted April 10, 2009.

Correspondence: Priya Sunil Kishnani, MD, Department of Pediatrics-Medical Genetics, Duke University Medical Center, Box 103856 DUMC, 595 LaSalle St., GSRB1, 4th Floor, Durham, NC 27710; e-mail: kishn001@mc.duke.edu

Supported by the Genzyme Corporation and the Duke Clinical Research Unit Program, National Center for Research Resources, National Institutes of Health (grant number RR024128).

Daniel Gruskin is currently at Department of Medical Affairs, Genzyme Corporation, Cambridge, MA 02142.

Deya Corzo is currently at Millennium: The Takeda Oncology Company, Cambridge, MA 02139.
The presentation and course of Pompe disease can vary widely. Patients may exhibit signs and symptoms as early as prenatally or in the first few days of life or as late as the sixth decade. The most severe and rapidly progressive form is designated as infantile-onset Pompe disease, in which patients generally develop significant clinical manifestations within the first months of life. If left untreated, most children with infantile-onset Pompe disease succumb to cardiac and/or respiratory failure before the age of $1 \mathrm{y}(1,4-6)$.

Enzyme replacement therapy with recombinant human alglucosidase alfa (rhGAA, Myozyme) was approved for treating patients with Pompe disease in 2006. Previous studies demonstrated that enzyme replacement therapy changes the natural history of Pompe disease in infants and children (7-12). The largest of these studies evaluated the effects of alglucosidase alfa in 18 young infants with severe infantileonset Pompe disease; these patients exhibited cardiomyopathy and profound deficiency of GAA activity at age $<7$ mo (12). Fifty-two weeks of treatment with alglucosidase alfa markedly improved survival, respiratory function, cardiomyopathy, and, among a subset of patients, motor function, compared with an untreated historical control group (12). This report describes the long-term effects of continued alglucosidase alfa treatment (up to $3 \mathrm{y}$ ) in the same cohort. These data represent a substantial addition to the literature, as long-term enzyme replacement outcome data were previously available for only four cases of infantile-onset Pompe disease (9).

\section{METHODS}

Study design and treatment. The design of the 52-wk open-label study has been described in detail elsewhere (12). Briefly, patients must have had

\footnotetext{
Abbreviations: AIMS, Alberta Infant Motor Scale; CRIM, cross-reacting immunologic material; GAA, acid $\alpha$-glucosidase; IAR, infusion-associated reactions; LVM, left ventricular mass; rhGAA, recombinant human acid $\alpha$-glucosidase
} 
documented symptoms of infantile-onset Pompe disease and been $<7$ mo old at enrollment. Patients with respiratory insufficiency, heart failure, or any prior replacement therapy with GAA were excluded. A closely matched untreated historical control group of 61 infants who had infantile-onset Pompe disease was used as a comparator population (12).

Parents or guardians gave written informed consent for patients' participation and consent could be withdrawn at any time. Local Institutional Review Boards or Independent Ethics Committees approved protocols and consent forms at each of the primary and extension study sites.

Alglucosidase alfa was supplied by Genzyme Corporation (Cambridge, MA). Eligible patients were randomized in a $1: 1$ ratio to receive i.v. infusions of alglucosidase alfa at either 20 or $40 \mathrm{mg} / \mathrm{kg}$ every other week (12). Fifty-two weeks after the last patient was randomized to treatment, patients were eligible to participate in an extension study, where they continued to receive alglucosidase alfa at the same dose to which they were originally assigned. Patients were treated in 52-wk modules until the study was terminated June 15, 2006, shortly after Myozyme was approved for commercial use. Because patients were enrolled over a period of $1 \mathrm{y}$ and survived to different ages, the duration of data collection varied among patients, ranging from 60 to $150 \mathrm{wk}$.

Clinical assessments of safety. Safety data were analyzed for the duration of treatment. Patients were observed and vital signs were monitored during each infusion and for $2 \mathrm{~h}$ afterward. Safety assessments included evaluating blood and urine chemistry, vital signs, 12-lead electrocardiograms, and the incidence and nature of adverse events, including infusion associated reactions (IARs). The development of anti-rhGAA IgG antibodies was assessed in serum samples taken before each infusion every $4 \mathrm{wk}$ from baseline through week 24 and subsequently at 12-wk intervals, as described previously (11).

Clinical assessments of efficacy. Survival and ventilator use (invasive and noninvasive) were analyzed at ages 24 and $36 \mathrm{mo}$; all other efficacy data were analyzed with respect to changes from baseline to the final assessment. Left ventricular mass (LVM) and other cardiac parameters were evaluated by echocardiogram at 12 -wk intervals. Echocardiograms were centrally read by a pediatric cardiologist who was blinded to dose, patient, and time point. Motor development was centrally evaluated using the Alberta Infant Motor Scale (AIMS) (13) until patients reached the maximum total AIMS score to allow for continuous monitoring on this scale.

Anti-rhGAA antibody and inhibitory antibody testing. The presence of anti-rhGAA IgG antibodies was assessed using enzyme-linked immunosorbent assays and confirmed using radioimmunoprecipitation, as described previously (11). Serum samples from seropositive patients were retrospectively analyzed for inhibition of rhGAA enzymatic activity and uptake in vitro (14).

Statistical methods. The Kaplan-Meier method was used to calculate the proportion of patients with an event (i.e. death or ventilator use) (15). The Cox regression analysis was used to compare the risk of an event (i.e. death or ventilator use) in alglucosidase alfa-treated patients to the untreated historical control group (16). Statistical analyses were performed using the SAS statistical software system (version 8).

Eighteen infants participated in the initial open-label trial (12). As shown in Figure 1, 16 surviving patients enrolled in the extension study. One patient, a male in the $20 \mathrm{mg} / \mathrm{kg}$ dose group, died at the age of $19.8 \mathrm{mo}$, after receiving alglucosidase alfa for $61 \mathrm{wk}$, but before the extension study began. A female patient in the $40 \mathrm{mg} / \mathrm{kg}$ dose group completed the initial open-label study, but did not enroll in the extension study after becoming ventilated; the patient continued therapy in an international Expanded Access Program until her

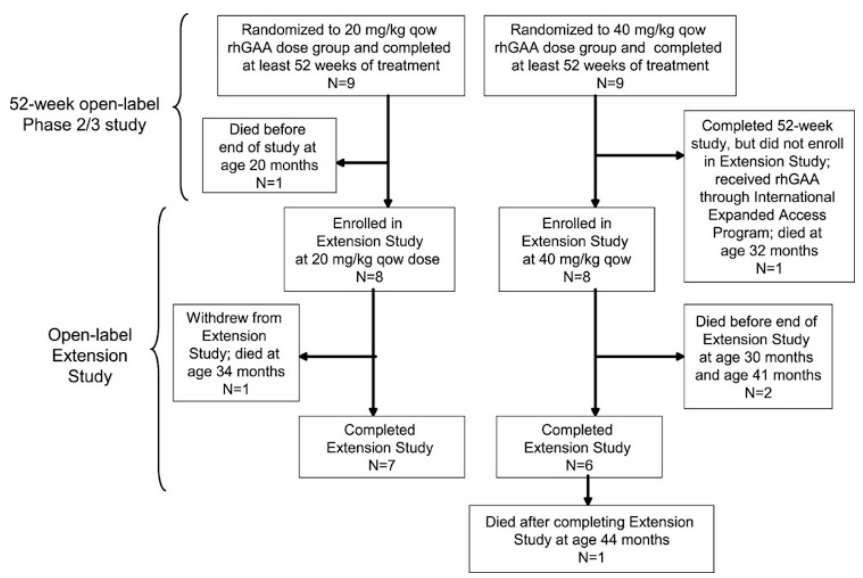

Figure 1. Disposition of patients in $20 \mathrm{mg} / \mathrm{kg}$ qow and $40 \mathrm{mg} / \mathrm{kg}$ qow groups. death at age $32 \mathrm{mo}$. Although these two patients did not enroll in the extension study, available data from baseline to their last assessment are included in these analyses, for completeness.

\section{RESULTS}

The duration of alglucosidase alfa treatment ranged from 1.1 to $3.0 \mathrm{y}$, with a median duration of treatment of $2.3 \mathrm{y}$. All 18 patients who participated in the initial open-label study survived to the age of 18 mo (12). As shown in Figure 1, five of the 18 patients died before the end of the extension study. Patient $\mathrm{C}$ discontinued from the initial study but was receiving alglucosidase alfa through an international Expanded Access Program at the time of death. Patient D died during the initial study, and patients A and Q died during the extension study. Patient $\mathrm{L}$ withdrew from the extension study after a decline in clinical status, at the request of family. The survival analyses do not include the death of a sixth patient, patient $\mathrm{P}$, who was reported to have died $\sim 1 \mathrm{y}$ after completing the extension study.

Survival status for individual patients is shown in Table 1. Seventeen of the 18 patients reached the age of $24 \mathrm{mo}$, for a survival rate of $94.4 \%$ (95\% CI: 83.9 to 100). The survival rate at age 36 mo was $72 \%$ (95\% CI: 47.9 to 96.0 ), including seven of the 18 patients who reached age 36 mo by the end of the study. Four patients died before age $36 \mathrm{mo}$, including patient $\mathrm{D}$ at $19.8 \mathrm{mo}$, patient $\mathrm{C}$ at $31.9 \mathrm{mo}$, patient $\mathrm{L}$ at $34.3 \mathrm{mo}$, and patient $\mathrm{Q}$ at $30.1 \mathrm{mo}$. The other seven patients were rightcensored from this analysis because they had not reached age 36 mo by the end of the study, although they were alive at that time, at ages ranging from 27.1 to $35.7 \mathrm{mo}$. In contrast, only one of 61 patients in the untreated historical control group survived to the ages of 24 and 36 mo (1.9\%; 95\% CI: 0 to 5.5 ). Survival rate by age estimated by the Kaplan-Meier method is shown in Figure $2 A$.

Ventilation status for individual patients at the end of the study or at the time of their death is shown in Table 1. Three of the 18 patients (patients $\mathrm{A}, \mathrm{P}$, and $\mathrm{R}$ ) required invasive ventilator support at age $18 \mathrm{mo}$ (12). Six of the 18 patients (the three noted above plus patients $\mathrm{C}, \mathrm{E}$, and $\mathrm{L}$ ) required invasive ventilator support at age $24 \mathrm{mo}$ or at the time of death. A total of nine patients (the six noted above plus patients $\mathrm{D}, \mathrm{M}$, and Q) required invasive ventilator support at age $36 \mathrm{mo}$, at the time of death, or at the end of the study. The age at which patients became dependent on invasive ventilator support ranged from 9.1 to 29.6 mo. Overall, 12 patients remained free of invasive ventilation at the age of $24 \mathrm{mo}$, and nine patients remained free of invasive ventilation at age $36 \mathrm{mo}$, including four patients who were right-censored from this analysis because they had not reached age 36 mo by the end of the study, though they remained free of invasive ventilatory support at that time. The Kaplan-Meier invasive ventilation-free survival rate (the primary efficacy endpoint) was $66.7 \%$ (95\% CI: 44.9 to 88.4 ) at age 24 mo and $49.4 \%$ (95\% CI: 26.0 to 72.8 ) at age 36 mo. This is far greater than the overall survival rate of untreated patients (with or without ventilation), as shown in Figure $2 B$.

The proportion of patients who were alive and free of any ventilator support (invasive or noninvasive) was evaluated as 
Table 1. Survival, ventilation status, and motor function in individual patients

\begin{tabular}{|c|c|c|c|c|c|c|c|}
\hline \multirow[b]{2}{*}{ Patient ID } & \multirow[b]{2}{*}{ Dose } & \multirow[b]{2}{*}{ Survival status } & \multirow{2}{*}{$\begin{array}{l}\text { Age at end of study } \\
\text { (or death) in months }\end{array}$} & \multirow[b]{2}{*}{ Ventilation status } & \multicolumn{3}{|c|}{ Motor function at final AIMS assessment } \\
\hline & & & & & Age (mo) & Study week & Motor function status \\
\hline A & 40 & Died & 40.7 & Invasive & 35.7 & Week 130 & Minimal gains \\
\hline B & 20 & Alive & 41.5 & No ventilation & 29.5 & Week 104 & Walking \\
\hline $\mathrm{C}^{* \dagger}$ & 40 & Died & 31.9 & Invasive & 26.4 & Week 90 & Minimal gains \\
\hline $\mathrm{D} \ddagger$ & 20 & Died & 19.8 & Invasive & 17.8 & Week 52 & Minimal gains \\
\hline $\mathrm{E}$ & 20 & Alive & 39.4 & Invasive & 37.6 & Week 142 & Minimal gains \\
\hline $\mathrm{F}$ & 40 & Alive & 39.4 & No ventilation & 21.8 & Week 64 & Walking \\
\hline $\mathrm{G}$ & 40 & Alive & 35.7 & No ventilation & 16.2 & Week 52 & Walking \\
\hline $\mathrm{H}$ & 20 & Alive & 36.7 & No ventilation & 35.7 & Week 130 & Walking \\
\hline I & 20 & Alive & 36.1 & No ventilation & 35.7 & Week 130 & Walking \\
\hline $\mathrm{J}$ & 40 & Alive & 38.1 & No ventilation & 36.7 & Week 130 & Sitting \\
\hline $\mathrm{K}$ & 20 & Alive & 34.1 & No ventilation & 33.0 & Week 116 & Sitting \\
\hline $\mathrm{L} \uparrow$ & 40 & Died & 34.3 & Invasive & 25.1 & Week 104 & Minimal gains \\
\hline $\mathrm{M}^{\dagger}$ & 20 & Alive & 30.0 & Invasive & 33.0 & Week 116 & Sitting \\
\hline $\mathrm{N}$ & 40 & Alive & 28.8 & No ventilation & 16.0 & Week 34 & Walking \\
\hline $\mathrm{O}$ & 20 & Alive & 32.8 & No ventilation & 32.7 & Week 116 & Walking \\
\hline $\mathrm{P} \S$ & 40 & Alive & 32.0 & Invasive & 30.6 & Week 104 & Minimal gains \\
\hline $\mathrm{Q}$ & 40 & Died & 30.1 & Invasive & 24.2 & Week 78 & Sitting \\
\hline $\mathrm{R}$ & 20 & Alive & 27.1 & Invasive & 25.6 & Week 104 & Minimal gains \\
\hline
\end{tabular}

* Patient $\mathrm{C}$ completed the initial study but did not enroll in the extension study. This patient continued to receive alglucosidase alfa through an international expanded access program.

$\dagger$ Patients C, L, and M each exhibited some level of walking skills at earlier assessments. Each of these patients experienced declines in respiratory function that led to invasive ventilation and the subsequent loss of walking skills.

$\ddagger$ Patient D died during the initial 52-week study.

$\S$ Patient P was alive at the end of the extension study but died in May 2007, 1 y after completing the study, at age 44 mo.
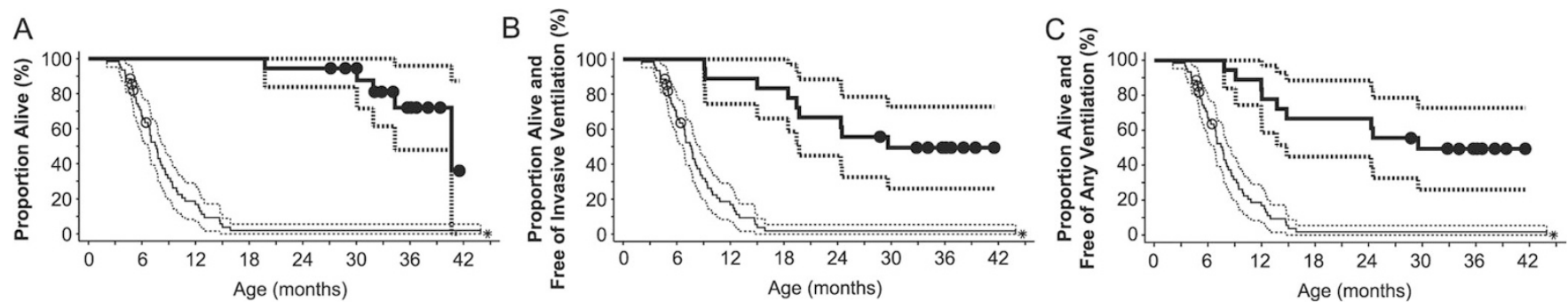

Figure 2. Kaplan-Meier analyses of survival, survival free of invasive ventilation, and survival free of any ventilation. In each panel, thick solid lines show the Kaplan-Meier estimates for the treated patient group; thin solid lines show those for the historical control group, with 95\% CI given by the corresponding dashed lines. Solid circles indicate right-censored observations. (A) Kaplan-Meier estimate of time from date of birth to death. Seven patients were right-censored from this analysis because they had not reached age 36 mo by the end of the study, although they remained alive at that time. (B) Kaplan-Meier estimate of time from birth to invasive ventilator use or death. Four patients were right-censored from this analysis because they had not reached age 36 mo by the end of the study, although they remained free of invasive ventilation that time. $(C)$ Kaplan-Meier estimate of time from birth to any ventilator use or death. Four patients were right-censored from this analysis because they had not reached age 36 mo by the end of the study, although they remained free of any ventilation that time. * indicates that 1 patient from the historical control group remained alive at 36 mo of age; this patient died at age 44 mo.

a secondary endpoint. No additional patients required noninvasive ventilatory support at the ages of 24 or 36 mo or at the time of death. Thus, the Kaplan-Meier ventilation-free survival rate was the same as the invasive ventilation-free survival rate: $66.7 \%$ (95\% CI: 44.9 to 88.4 ) at age 24 mo and $49.4 \%$ (95\% CI: 26.0 to 72.8 ) at age 36 mo; again, this is much higher than the overall survival rate of untreated patients (with or without ventilation), as shown in Figure $2 C$.

Cox regression analyses demonstrated that alglucosidase alfa reduced the risk of death by $95 \%$ (hazard ratio of 0.05 , 95\% CI: 0.02 to 0.14 ); the risk of invasive ventilation or death by $91 \%$ (hazard ratio of $0.09,95 \%$ CI: 0.04 to 0.22 ); and the risk of any type of ventilation or death by $87 \%$ (hazard ratio of $0.13,95 \%$ CI: 0.06 to 0.29 ). No difference in the effects of alglucosidase alfa on survival or ventilator-free survival was observed between the two dose groups.
Cardiomyopathy was defined as an LVM value $>2 \mathrm{SD}$ from the normal mean. Mean LVM Z-scores progressively decreased from 7.1 to 3.3 during the first 52 wk of alglucosidase alfa treatment (12). During the extension study, mean LVM $Z$-scores continued to gradually decrease. At the end of the extension study, mean LVM $Z$-scores remained stable at slightly above the upper limit of the normal range (2.0), as shown in Figure 3. LVM Z-scores for individual patients are shown in Table 2. Among individual patients, seven had LVM Z-scores within the normal range at the time of the final assessment (patients B, G, H, I, J, N, and $\mathrm{O}$ ) and all but one of the patients (patient L) showed reductions in LVM of at least $1 \mathrm{Z}$-score from the first assessment to the time of the final assessment (Table 2). Patient L had exhibited more robust improvement at $52 \mathrm{wk}$ (12) but worsening cardiomyopathy thereafter. This patient eventually withdrew from the study 


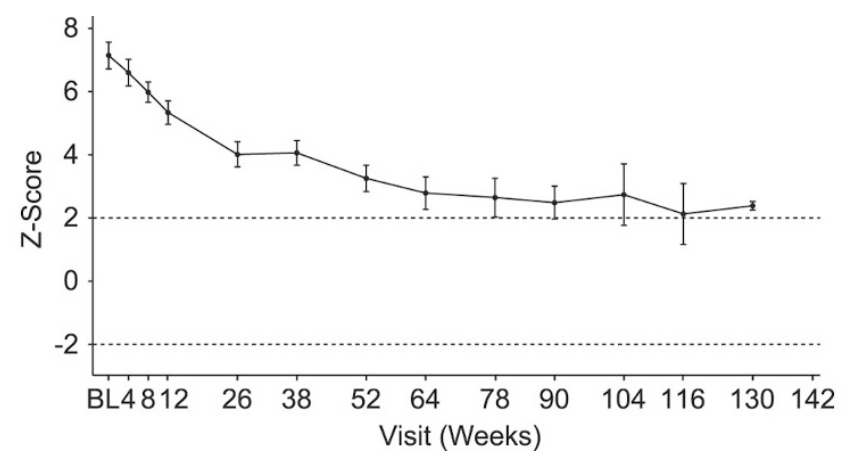

Figure 3. Mean left ventricular mass $Z$-scores of treated patients from baseline to week 52; vertical bars represent SE.

Table 2. Effect of alglucosidase alfa treatment on left ventricular mass in individual patients

\begin{tabular}{cccccc}
\hline $\begin{array}{c}\text { Patient } \\
\text { ID }\end{array}$ & $\begin{array}{c}\text { Dose } \\
\text { D-score at } \\
\text { baseline* }\end{array}$ & $\begin{array}{c}\text { LVM } \\
\text { Z-score at final } \\
\text { assessment }\end{array}$ & $\begin{array}{c}\text { Change in } \\
\text { LVM Z-score } \\
\text { from baseline }\end{array}$ & $\begin{array}{c}\text { Study week of } \\
\text { final LVM } \\
\text { assessment }\end{array}$ \\
\hline $\mathrm{A}$ & 40 & 8.39 & 2.06 & -6.33 & Week 124 \\
$\mathrm{B}$ & 20 & $3.03^{*}$ & $\mathbf{1 . 9 3}$ & -1.10 & Week 98 \\
$\mathrm{C} \dagger$ & 40 & $7.04^{*}$ & 2.94 & -4.10 & Week 26 \\
$\mathrm{D} \dagger$ & 20 & 9.27 & 4.36 & -4.91 & Week 52 \\
$\mathrm{E}$ & 20 & 6.73 & 2.52 & -4.21 & Week 130 \\
$\mathrm{F}$ & 40 & 8.99 & 2.25 & -6.74 & Week 130 \\
$\mathrm{G}$ & 40 & 8.00 & $\mathbf{1 . 8 1}$ & -6.19 & Week 116 \\
$\mathrm{H}$ & 20 & 7.88 & $\mathbf{0 . 4 7}$ & -7.41 & Week 116 \\
$\mathrm{I}$ & 20 & 6.84 & $\mathbf{1 . 4 6}$ & -5.38 & Week 64 \\
$\mathrm{J}$ & 40 & 6.60 & $\mathbf{0 . 7 6}$ & -5.84 & Week 116 \\
$\mathrm{K}$ & 20 & 7.77 & 2.19 & -5.58 & Week 104 \\
$\mathrm{L}$ & 40 & 6.50 & 5.84 & -0.66 & Week 116 \\
$\mathrm{M}$ & 20 & 6.33 & 2.91 & -3.42 & Week 84 \\
$\mathrm{N}$ & 40 & 2.62 & $\mathbf{1 . 0 9}$ & -1.53 & Week 104 \\
$\mathrm{O}$ & 20 & 5.43 & $\mathbf{0 . 7 6}$ & -4.67 & Week 104 \\
$\mathrm{P}$ & 40 & 7.57 & 4.57 & -3.00 & Week 90 \\
$\mathrm{Q}$ & 40 & $7.55^{*}$ & 2.47 & -5.08 & Week 90 \\
$\mathrm{R}$ & 20 & 8.23 & 7.02 & -1.21 & Week 104 \\
\hline
\end{tabular}

Shaded rows indicate patients who had died prior to database lock (November 30, 2006), as shown in Table 1. LVM $Z$-score values in bold are within normal limits (LVM values within $2 \mathrm{SD}$ from the normal mean (i.e. $Z$-score -2 to +2$){ }^{12}$

* Baseline LVM values were unavailable for Patients B, C, and Q. For these patients, the first available LVM values are shown (from study week 4 or week 8).

$\dagger$ Patients C and D did not enroll in the extension study (see Table 1).

after progression to invasive ventilation. No difference in the effects of alglucosidase alfa on cardiomyopathy was observed between the two dose groups.

As shown in Table 1, seven of the 18 patients (patients B, F, G, H, I, N, and O) gained motor skills and were walking by the time of their final AIMS assessment. An additional four patients (patients J, K, M, and Q) gained motor skills and were sitting independently at that time. The remaining seven patients (patients A, C, D, E, L, P, and R) made minimal motor gains, or they were unable to achieve sustained motor gains and had very limited gross motor skills. Each of these seven patients had become dependent on invasive ventilation at the end of the extension study or at the time of their deaths. All but one of the seven patients who had learned to walk by study week 52 (12) retained this skill by the end of the study. Patient C, who was walking at study week 52 (12), became dependent on invasive ventilation at age 24 mo (study week 75) and lost the ability to walk. Patients $\mathrm{L}$ and $\mathrm{M}$ had each gained standing skills by week 52 (12), which were subsequently lost. No difference in motor function was observed between patients in the two dose groups.

Eleven of the 18 patients experienced 224 IARs, defined as any treatment-related $\mathrm{AE}$ that occurred during an infusion or within $2 \mathrm{~h}$ after the infusion. All IARs were mild or moderate in intensity; none were severe. The most common IARs were urticaria (47 events), fever (27 events), and decreased oxygen saturation ( 24 events). IARs were typically managed by slowing or interrupting infusions and all 11 patients who experienced IARs recovered without sequelae.

Overall, more IARs were reported for patients in the 40 $\mathrm{mg} / \mathrm{kg}$ dose group. Five patients in the $20 \mathrm{mg} / \mathrm{kg}$ dose group experienced 47 events ( $21 \%$ of all IARs) and six patients in the $40 \mathrm{mg} / \mathrm{kg}$ dose group experienced 177 events (79\% of all IARs). Most of these events (65\%) were experienced by two patients, both in the $40 \mathrm{mg} / \mathrm{kg}$ dose group: Patient C (43 events) and Patient Q (102 events), as shown in Table 3. These patients experienced recurrent episodes of urticaria, flushing, fever, agitation, rash, tachypnoea, cough, and vomiting at multiple infusions. The events were managed by slowing the infusion rate of alglucosidase alfa or temporarily stopping the infusions and administering antihistamines, antipyretics, and/or corticosteroids. As shown in Table 3, both of these patients also exhibited sustained high anti-rhGAA IgG titer levels.

Four of the 18 patients (patients $\mathrm{C}, \mathrm{L}, \mathrm{P}$, and R) did not exhibit any detectable endogenous full-length or partial GAA protein product, designated as cross-reacting immunologic material (CRIM) (12). Serum samples from three of the four CRIM-negative patients (patients $\mathrm{C}, \mathrm{L}$, and $\mathrm{P}$ ) exhibited in vitro inhibitory antibody activity, as determined by analysis of enzyme activity or rhGAA uptake assays. Overall, patients in the $40 \mathrm{mg} / \mathrm{kg}$ dose group tended to have higher anti-rhGAA IgG titers (Table 3). However, because of the small number of CRIM-negative patients in this study and the fact that three of the four CRIM-negative patients (patients $\mathrm{C}, \mathrm{L}$, and $\mathrm{P}$ ) were randomized to the $40 \mathrm{mg} / \mathrm{kg}$ dose group, statistical analyses regarding the relationship among dose, immune response, and IARs were not feasible.

\section{DISCUSSION}

This study includes the largest number of patients and represents one of the longest trials of rhGAA enzyme replacement therapy to date for the most rapidly progressing form of infantile-onset Pompe disease. In the absence of treatment, the life expectancy of children with classical infantile-onset Pompe disease is usually less than $1 \mathrm{y}$, with death typically caused by cardiac and/or respiratory failure $(1,5,6)$. A report based on the first 52 wk of treatment in this cohort demonstrated that alglucosidase alfa treatment significantly improved survival, respiratory function, cardiomyopathy, and, in a subset of patients, motor function, up to the age of 18 mo (12). This report describes the status of these patients through up to $3 \mathrm{y}$ of alglucosidase alfa treatment. Seventeen of the 18 
Table 3. Summary of immunological characteristics and infusion-associated reactions

\begin{tabular}{|c|c|c|c|c|c|c|c|}
\hline Patient ID & $\begin{array}{l}\text { Dose } \\
\text { group }\end{array}$ & $\begin{array}{l}\text { Number of infusions } \\
\text { received }\end{array}$ & $\begin{array}{l}\text { Maximum anti-rhGAA } \\
\text { IgG titer level reported }\end{array}$ & $\begin{array}{l}\text { Anti-rhGAA IgG titer } \\
\text { level at final study visit }\end{array}$ & $\begin{array}{l}\text { Number } \\
\text { of IARs }\end{array}$ & $\begin{array}{l}\text { CRIM } \\
\text { status }\end{array}$ & $\begin{array}{l}\text { Inhibitory antibody activity } \\
>20 \% \text { in serum }\end{array}$ \\
\hline A & 40 & 76 & 204,800 & 51,200 & 4 & + & No \\
\hline $\mathrm{B}$ & 20 & 74 & 12,800 & 200 & 2 & + & No \\
\hline $\mathrm{C}^{*}$ & 40 & 41 & 409,600 & 409,600 & 43 & - & Yes \\
\hline$D^{*}$ & 20 & 31 & 6,400 & 200 & 4 & + & No \\
\hline E & 20 & 71 & 1,600 & 200 & 5 & + & No \\
\hline F & 40 & 69 & 3,200 & 400 & 0 & + & No \\
\hline G & 40 & 67 & 400 & 100 & 0 & + & No \\
\hline $\mathrm{H}$ & 20 & 65 & 800 & 400 & 0 & + & No \\
\hline I & 20 & 65 & 800 & 400 & 14 & + & No \\
\hline $\mathrm{J}$ & 40 & 63 & 25,600 & 1600 & 4 & + & No \\
\hline $\mathrm{K}$ & 20 & 58 & N/A & N/A & 0 & + & No \\
\hline $\mathrm{L}$ & 40 & 58 & $3,276,800$ & $1,638,400$ & 14 & - & Yes \\
\hline M & 20 & 62 & 12,800 & 3,200 & 0 & + & No \\
\hline $\mathrm{N}$ & 40 & 59 & N/A & N/A & 0 & + & No \\
\hline $\mathrm{O}$ & 20 & 53 & 400 & 100 & 0 & + & No \\
\hline $\mathrm{P}$ & 40 & 53 & 409,600 & 102,400 & 10 & - & Yes \\
\hline Q & 40 & 53 & 409,600 & 51,200 & 102 & + & No \\
\hline $\mathrm{R}$ & 20 & 53 & 102,400 & $25,600 \dagger$ & 22 & - & No \\
\hline
\end{tabular}

N/A, not applicable; Patients $\mathrm{K}$ and $\mathrm{N}$ remained seronegative at all assessments. Note that the number of IARs represents individual AEs and may include the same term multiple times. Patients $\mathrm{C}$ and $\mathrm{Q}$ experienced recurrent IARs at multiple infusions. Shaded rows indicate patients who had died prior to database lock (November 30, 2006), as shown in Table 1.

* Patients C and D did not enroll in the extension study (see Table 1).

$\dagger$ No IgG titer level was available for Patient R at the final study visit; the value shown reflects titer levels measured at week 38 .

patients survived to age 24 mo, whereas only one of 61 untreated patients in the historical control group survived to this age. Over the course of the study, alglucosidase alfa treatment markedly improved overall survival, as well as ventilator-free and invasive ventilator-free survival. Cox regression analyses demonstrated that alglucosidase alfa reduced the risk of death by $95 \%$, the risk of invasive ventilation or death by $91 \%$, and the risk of any type of ventilation or death by $87 \%$. These were conservative comparisons, as patients' ventilator-free survival (invasive or any ventilation) was compared with the overall survival (without regard to ventilation status) in the historical untreated cohort.

Deficiency of GAA leads to extensive accumulation of glycogen in cardiac muscle. Untreated patients exhibit cardiomyopathy and frequently succumb to cardiorespiratory failure $(1,5,6)$. In contrast, 17 of the 18 treated patients in this study exhibited substantial reductions in LVM from baseline to the final assessment, and seven patients had LVM values within normal limits at that time. Three of the four CRIM-negative patients exhibited less improvement in LVM (LVM Z-score > 4 at their final assessment), whereas only one of the 14 CRIM-positive patients had LVM Z-scores $>4$ at their final assessment. Overall, long-term alglucosidase alfa treatment results in sustained improvement in cardiomyopathy. This likely plays an important role in the extended survival observed in response to alglucosidase alfa treatment, regardless of CRIM or ventilatory status.

Accumulation of glycogen in skeletal muscle is associated with severe muscle weakness and hypotonia in patients with Pompe disease (1). In infants, this generally prevents the acquisition of key gross motor skills normally exhibited by children, such as rolling, independent sitting, and walking.
Eleven patients exhibited a steady acquisition of motor skills, including seven who sustained the ability to walk and four who were sitting independently at their final assessment. This represents a major departure from the natural progression of infantile-onset Pompe disease, where children seldom acquire significant gross motor skills. However, seven children had not acquired substantial gross motor skills at the end of the study or lost significant motor skills acquired during treatment, such as ambulation. Each of these seven patients also required invasive ventilation at the end of the study or at the time of their deaths, suggesting that disease progression affects both respiratory and skeletal muscle function. Interestingly, each of the seven patients who had LVM Z-scores within the normal range at the time of the final assessment also exhibited sustained gains in gross motor function over the course of the study; four were walking and three had learned to sit independently.

No differences were observed between the two dose groups in terms of the effects of long-term alglucosidase alfa treatment on the proportion of patients with prolonged survival, ventilation-free survival, or degree of improvement in cardiomyopathy or motor function.

Therapeutic recombinant proteins frequently induce an immune response, the extent of which varies between individuals. Patients in the $40 \mathrm{mg} / \mathrm{kg}$ dose group tended to develop higher anti-rhGAA IgG titers than patients in the $20 \mathrm{mg} / \mathrm{kg}$ dose group. However, three of the four CRIM-negative patients, all of whom exhibited high anti-rhGAA IgG titers, were randomized to the $40 \mathrm{mg} / \mathrm{kg}$ dose group. Given the small number of patients in this study and the various confounding factors involved, it is not clear whether a higher dose is more immunogenic. However, this and previous published reports contribute to a growing body of evidence suggesting that 
CRIM-negative patients, who produce little or no endogenous GAA, develop a stronger immunologic response against alglucosidase alfa than CRIM-positive patients, who produce some form of endogenous GAA protein $(7,11,12,17,18)$. Three of the four CRIM-negative patients also exhibited in vitro inhibitory antibody activity, which could impact the long-term efficacy of alglucosidase alfa. Indeed, each of these three patients showed signs of clinical decline during treatment, became dependent on invasive ventilation, and eventually died; patient $\mathrm{C}$ died at age $31.9 \mathrm{mo}$, patient $\mathrm{L}$ died at 34.3 mo, and patient $\mathrm{P}$ died after completing the study, at age 44.4 mo. Thus, there is a relationship among CRIM status, high antibody titers, inhibitory antibody activity, and long-term clinical outcome in Pompe disease.

In various clinical trials and expanded access programs, $\sim 14 \%$ of patients treated with alglucosidase alfa (38 of 280 patients) developed allergic reactions involving at least two of the following three body systems: cutaneous, respiratory, or cardiovascular (19). The two patients who experienced the highest number of IARs in this study (patients $\mathrm{C}$ and Q) also exhibited signs and/or symptoms suggestive of allergic reactions. Patient C, who was CRIM-negative, experienced urticaria, cough, and serious rales, and patient $\mathrm{Q}$, who was CRIM-positive, experienced recurrent events of hypotension, rash, cough, and urticaria on multiple occasions. Both the patients were receiving the $40 \mathrm{mg} / \mathrm{kg}$ dose of alglucosidase alfa and both the patients had high antibody titers. It is possible that some IARs experienced by these two patients could be IgG-mediated reactions and may have occurred due to development of IgG antibodies that bind to complement and release specific mediators from complement activation. IARs were generally dose-related or infusion raterelated. Each patient tested negative for $\operatorname{IgE}$ and positive for complement on multiple occasions, with serum tryptase levels that were slightly elevated (patient $\mathrm{C}$ ) or within the normal range (patient Q) (data not shown). Further studies of more patients with long-term data will be necessary to delineate possible relationships among dose, CRIM status, antibody titers, and IARs.

Taken together, these findings show that the beneficial effects of alglucosidase alfa in children with infantile-onset Pompe disease are sustained after prolonged treatment. All 18 patients who enrolled in the initial study survived significantly longer and with fewer ventilation events than untreated historical control patients and improvements in cardiomyopathy were generally sustained over the course of the extension study. However, morbidity and mortality remain substantial, with a $28 \%$ mortality rate and a $51 \%$ invasive ventilation rate at age 36 mo. The effect of treatment on gross motor function was somewhat variable. Eleven patients exhibited clinically meaningful gains and seven patients either did not acquire or did not sustain substantial gains in motor function. Various factors, including invasive ventilation, CRIM status, and patients' immunologic response to alglucosidase alfa, may have contributed to the poorer motor skills exhibited by these children. Interestingly, each of the seven patients who were walking at the end of the study exhibited little or no cardiomyopathy and relatively low $\operatorname{IgG}$ antibody titers at the final visit.

Increasing evidence suggests that CRIM-negative patients are at considerable risk of developing a high, sustained immunologic response that may reduce the clinical benefit of alglucosidase alfa and worsen the long-term outcome in this subpopulation of patients $(11,12,18)$. However, the favorable risk-to-benefit ratio suggests that infants with rapidly progressive Pompe disease should be treated with alglucosidase alfa. Immune modulation strategies to control the development of antibodies during long-term administration of alglucosidase alfa could be a viable option in high risk, CRIM-negative patients $(18,20)$.

The young ages at which these patients began receiving alglucosidase alfa and the onset of therapy at early stages of disease progression (i.e. before ventilation or cardiac failure) may have contributed to the robust improvements in survival, cardiac, and motor function observed. Findings from this and other published reports with shorter follow-up periods demonstrate that alglucosidase alfa is an effective treatment for most patients with infantile-onset Pompe disease. However, although this treatment provides dramatic improvement, it is clearly not a cure; further investigation into the profound individual variability in response to treatment is needed.

Acknowledgments. We thank our colleagues Dr. Dennis Bartholomew, Dr. Barry Byrne, Dr. Geoffroy de La Gastine, Dr. Wuh-Ling Hwu, Dr. Marc Nicolino, Dr. Carolyn Spencer, and Dr. J. Edmond Wraith, who treated patients during the initial 52-week study. We also thank the study coordinators, our colleagues at Genzyme Corporation and the GCRC staff at Duke University. The authors are especially grateful to the patients who participated in this clinical study and their families.

\section{REFERENCES}

1. Hirschhorn R, Reuser AJ 2001 Glycogen storage disease type II: acid $\alpha$-glucosidase (acid maltase) deficiency. In: Scriver CR, Beaudet AL, Sly WS, Valle D (eds) The Metabolic and Molecular Bases of Inherited Disease. 8th ed. McGraw Hill, New York, pp 3389-3420

2. Koeberl DD, Kishnani PS, Chen YT 2007 Glycogen storage disease types I and II: treatment updates. J Inherit Metab Dis 30:159-164

3. Kishnani PS, Howell RR 2004 Pompe disease in infants and children. J Pediatr 144:S35-S43

4. Chen YT, Amalfitano A 2000 Towards a molecular therapy for glycogen storage disease type II (Pompe disease). Mol Med Today 6:245-251

5. van den Hout HM, Hop W, van Diggelen OP, Smeitink JA, Smit GP, Poll-The BT, Bakker HD, Loonen MC, de Klerk JB, Reuser AJ, van der Ploeg AT 2003 The natural course of infantile Pompe's disease: 20 original cases compared with 133 cases from the literature. Pediatrics 112:332-340

6. Kishnani PS, Hwu WL, Mandel H, Nicolino M, Yong F, Corzo D 2006 InfantileOnset Pompe Disease Natural History Study Group: a retrospective, multinational, multicenter study on the natural history of infantile-onset Pompe disease. J Pediatr 148:671-676

7. Amalfitano A, Bengur AR, Morse RP, Majure JM, Case LE, Veerling DL, Mackey J, Kishnani P, Smith W, McVie-Wylie A, Sullivan JA, Hoganson GE, Phillips JA 3rd, Schaefer GB, Charrow J, Ware RE, Bossen EH, Chen YT 2001 Recombinant human acid $\alpha$-glucosidase enzyme therapy for infantile glycogen storage disease type II: results of a phase I/II clinical trial. Genet Med 3:132-138

8. Van den Hout JM, Reuser AJ, de Klerk JB, Arts WF, Smeitink JA, Van der Ploeg AT 2001 Enzyme therapy for Pompe disease with recombinant human alphaglucosidase from rabbit milk. J Inherit Metab Dis 24:266-274

9. Van den Hout JM, Kamphoven JH, Winkel LP, Arts WF, De Klerk JB, Loonen MC, Vulto AG, Cromme-Dijkhuis A, Weisglas-Kuperus N, Hop W, Van Hirtum H, Van Diggelen OP, Boer M, Kroos MA, Van Doorn PA, Van der Voort E, Sibbles B, Van Corven EJ, Brakenhoff JP, Van Hove J, Smeitink JA, de Jong G, Reuser AJ, Van der Ploeg AT 2004 Long-term intravenous treatment of Pompe disease with recombinant human alpha-glucosidase from milk. Pediatrics 113:e448-e457 
10. Klinge L, Straub V, Neudorf U, Schaper J, Bosbach T, Görlinger K, Wallot M, Richards S, Voit T 2005 Safety and efficacy of recombinant acid alpha-glucosidase (rhGAA) in patients with classical infantile Pompe disease: results of a phase II clinical trial. Neuromuscul Disord 15:24-31

11. Kishnani PS, Nicolino M, Voit T, Rogers RC, Tsai AC, Waterson J, Herman GE, Amalfitano A, Thurberg BL, Richards S, Davison M, Corzo D, Chen YT 2006 Results from a phase II trial of Chinese hamster ovary cell-derived recombinant human acid $\alpha$-glucosidase in infantile-onset Pompe disease. J Pediatr 149:89-97

12. Kishnani PS, Corzo D, Nicolino M, Byrne B, Mandel H, Hwu WL, Leslie N, Levine J, Spencer C, McDonald M, Li J, Dumontier J, Halberthal M, Chien YH, Hopkin R, Vijayaraghavan S, Gruskin D, Bartholomew D, van der Ploeg A, Clancy JP, Parini R, Morin G, Beck M, De la Gastine GS, Jokic M, Thurberg B, Richards S, Bali D, Davison M, Worden MA, Chen YT, Wraith JE 2007 Recombinant human acid [alpha]-glucosidase: major clinical benefits in infantile-onset Pompe disease [published correction appears in Neurology 2008; 71:1748]. Neurology 68:99-109, 2007

13. Piper MC, Darrah J 1994 Motor Assessment of the Developing Infant. W.B. Saunders, Philadelphia

14. Nicolino M, Byrne B, Wraith JE, Leslie N, Mandel H, Freyer DR, Arnold GL, Pivnick EK, Ottinger CJ, Robinson PH, Loo J-C, Smitka M, Jardine P, Tatò L,
Chabrol B, McCandless S, Kimura S, Mehta L, Bali D, Skrinar A, Morgan C, Rangachari L, Corzo D, Kishnani PS 2009 Clinical outcomes after long-term treatment with alglucosidase alfa in infants and children with advanced Pompe disease. Genet Med 11:210-219

15. Kaplan EL, Meier P 1958 Nonparametric estimation from incomplete observations. J Am Stat Soc 53:457-481

16. Cox DR 1972 Regression models and life tables (with discussion). J Roy Statist Soc Ser B Methodological 34:187-220

17. Mandel H, Gruber M, Goldsher D, Chistyakov A, Kaplan B, Zaaroor M, Hafner H 2007 Longer survival by enzyme replacement therapy unmasks the underrecognition of otoneurologic involvement in infantile-onset Pompe disease. Clin Ther 29:S109-S110

18. Sun B, Bird A, Young SP, Kishnani PS, Chen YT, Koeberl DD, Slonim AE, Bulone L, Ritz S, Goldberg T, Chen A, Martiniuk F 2007 Enhanced response to enzyme replacement therapy in Pompe disease after the induction of immune tolerance. Am J Hum Genet 81:1042-1049

19. 2006 Myozyme [package insert]. Genzyme Corporation, Cambridge, MA

20. Mendelsohn NJ, Messinger YH, Rosenberg AS, Kishnani PS 2009 Elimination of antibodies to recombinant enzyme in Pompe's disease. N Engl J Med 360:194-195 